\title{
Michael Lamsa
}

\section{Die Firma der Auslandsgesellschaft}

Bildung, Führung und Schutz der Firma von Auslandsgesellschaften in Deutschland unter besonderer Berücksichtigung des Europäischen Gemeinschaftsrechts

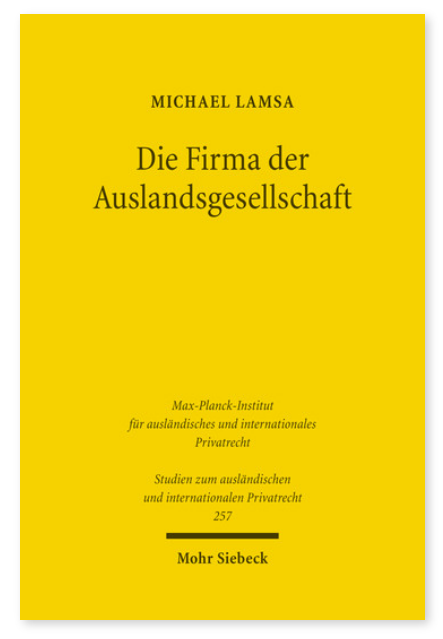

2011. XXXIV, 560 Seiten. StudIPR 257

ISBN 978-3-16-151442-5

DOI 10.1628/978-3-16-151442-5

eBook PDF $114,00 €$

ISBN 978-3-16-150648-2

fadengeheftete Broschur 114,00€
Das internationale Gesellschaftsrecht hat in Folge der Rechtsprechung des EuGH zur Niederlassungsfreiheit mit deren Entwicklung vom reinen Diskriminierungsverbot zum Beschränkungsverbot eine grundlegende Neuorientierung erfahren. Vor diesem Hintergrund erarbeitet Michael Lamsa für das internationale Firmenrecht ein konsistentes Anknüpfungsmodell für Bildung, Führung und Schutz der Firma von Auslandsgesellschaften. Dazu untersucht er das Firmenrecht im gemeinschaftsrechtlichen Regelungsgefüge unter besonderer Berücksichtigung der Vorgaben der Niederlassungsfreiheit und kennzeichenrechtlicher Regelungen des sekundären Gemeinschaftsrechts. Auf dieser Grundlage schlägt der Autor eine kumulative Anknüpfung vor. Er weist nach, dass das von ihm vorgeschlagene Anknüpfungsmodell insbesondere durch die Anwendung inländischen (deutschen) Firmenrechts nicht zu einer ungerechtfertigten Beeinträchtigung der Niederlassungsfreiheit von Auslandsgesellschaften führt.

Michael Lamsa Geboren 1976; Studium der Rechtswissenschaft und wirtschaftswissenschaftliche Zusatzausbildung für Juristen mit dem Schwerpunkten Finanzen und Steuern in Bayreuth; 2009 Promotion; derzeit Rechtsanwalt in Frankfurt.

Jetzt bestellen:

https://mohrsiebeck.com/buch/die-firma-der-auslandsgesellschaft-9783161514425?no_cache=1

order@mohrsiebeck.com

Telefon: +49 (0)7071-923-17

Telefax: $+49(0) 7071-51104$ 